\title{
RE: Darwish et al. "Ethibond Suture Granuloma Formation Following Repair of Acute Achilles Tendon Ruptures"
}

Amol Saxena ${ }^{1}$, Nicola Maffulli ${ }^{2}$

Journal of Foot and Ankle Surgery (Asia Pacific) (2021): 10.5005/jp-journals-10040-1151

Dear Editor,

We read with great interest the above-referenced article. In our paper from 2008, out of 219 various Achilles surgeries including acute repairs, we had approximately $3 \%$ suture and granuloma reactions, respectively. ${ }^{1}$ The granuloma formations occurred after 6 months. They were more associated with non-absorbable braided polyester suture. We admit, we did not do a statistical analysis at the time, including specifically analyzing rupture would complications. Nonetheless, we think this information would have enhanced the discussion and significance of Darwish et al.'s paper.

\section{Reference}

1. Saxena A, Maffulli N, Nguyen A, et al. Wound complications from surgeries pertaining to the Achilles tendon: an analysis of 219 surgeries. J Am Podiatr Med Assoc. 2008;98(2):95-101.
${ }^{1}$ Department of Sports Medicine, Sutter Health-Palo Alto Medical Foundation, Palo Alto, California, USA

${ }^{2}$ Department for Centre for Sports and Exercise Medicine, Queen Mary University of London, Barts and the London School of Medicine and Dentistry, Mile End Hospital, London, UK

Corresponding Author: Amol Saxena, Department of Sports Medicine, Sutter Health-Palo Alto Medical Foundation, Palo Alto, California, USA, Phone: +1 650853 2943, e-mail: heysax@aol.com

How to cite this article: Saxena A, Maffulli N. RE: Darwish et al. "Ethibond Suture Granuloma Formation Following Repair of Acute Achilles Tendon Ruptures". J Foot Ankle Surg (Asia Pacific) 2021;8(2):91. Source of support: Nil

Conflict of interest: None

() The Author(s). 2021 Open Access This article is distributed under the terms of the Creative Commons Attribution 4.0 International License (https:// creativecommons.org/licenses/by-nc/4.0/), which permits unrestricted use, distribution, and non-commercial reproduction in any medium, provided you give appropriate credit to the original author(s) and the source, provide a link to the Creative Commons license, and indicate if changes were made. The Creative Commons Public Domain Dedication waiver (http://creativecommons.org/publicdomain/zero/1.0/) applies to the data made available in this article, unless otherwise stated. 